\title{
Interpretar el sufrimiento: Walter Benjamin, Theodor W. Adorno y la cuestión de la verdad
}

\author{
Interpret suffering. Walter Benjamin, Theodor Adorno \\ and the question of truth
}

\author{
María Rita Moreno \\ Instituto de Ciencias Humanas, Sociales y \\ Ambientales (INCIHUSA) CONICET, Argentina \\ xmariaritamoreno@gmail.com
}

\begin{abstract}
Resumen
Este artículo postula que la criticidad de la epistemología elaborada por Walter Benjamin y Theodor W. Adorno se fundamenta no tanto en la reformulación de una praxis filosófica contra la razón moderna, sino principalmente en la metamorfosis del concepto de verdad. En concreto, se afirma que la crítica de la razón moderna efectuada por ambos pensadores se asocia a la determinación del núcleo temporal de la verdad como negatividad y duelo. En el contexto de una crisis racional, Benjamin y Adorno abren la posibilidad de una vinculación con la objetividad en la forma de una interpretación crítica de ese núcleo temporal. Ésta, vinculada con la dialéctica de la catástrofe moderna, se ocupa de exponer los fragmentos producidos por la super-determinación subjetivista regida por la lógica de la identidad. Para justificar esto, en primer lugar, explicamos la identificación realizada por ambos filósofos entre núcleo temporal de la verdad y el concepto de verdad luctuoso-negativa; imbricación que procura condensar las consecuencias de la constitución subjetivista de la razón. Luego, señalamos la conjugación de esa definición de la verdad con la producción del sufrimiento. A continuación, determinamos en qué sentido la negatividad de la verdad abre el carácter dialéctico de la catástrofe moderna. Por último, indicamos la necesaria asociación de semejante epistemología crítica a la apocatástasis histórica.
\end{abstract}

Palabras clave: núcleo temporal, verdad negativa, duelo, sufrimiento, catástrofe, interpretación crítica, Walter Benjamin, Theodor Adorno.

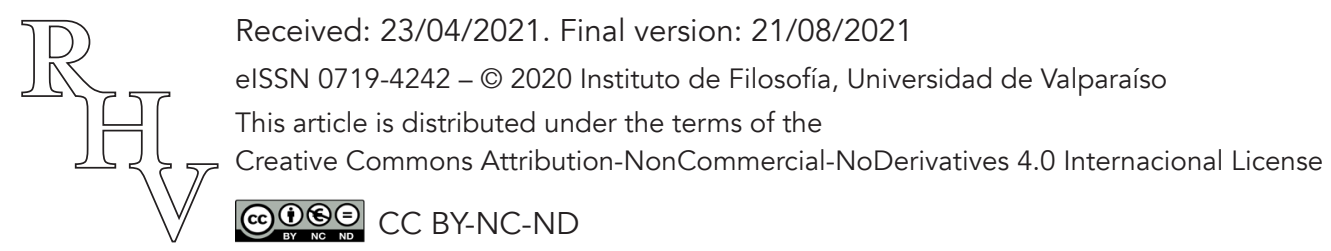


Interpretar el sufrimiento: Walter Benjamin, Theodor W. Adorno y la cuestión de la verdad

María Rita Moreno

\begin{abstract}
This article postulates that the criticality of epistemology elaborated by Walter Benjamin and Theodor W. Adorno is based not so much on the reformulation of a philosophical praxis against modern reason, but mainly on the metamorphosis of the concept of truth. Specifically, it is affirmed that the critique of modern reason carried out by both thinkers is associated with the determination of the temporal nucleus of truth as negativity and mourning. In the context of a rational crisis, Benjamin and Adorno open the possibility of a relationship with objectivity in the form of a critical interpretation of that temporal nucleus. This, linked to the dialectic of modern catastrophe, deals with exposing the fragments produced by the subjectivist super-determination governed by the logic of identity. To justify this, first, we explain the identification made by both philosophers between the temporal nucleus of truth and the concept of sad-negative truth; imbrication that tries to condense the consequences of the subjectivist constitution of reason. Then, we point out the conjugation of this definition of truth with the production of suffering. Next, we determine in what sense the negativity of the truth opens up the dialectical character of the modern catastrophe. Finally, we indicate the necessary association of such a critical epistemology with the historical apocatastasis.
\end{abstract}

Keywords: nucleus of time, negative truth, mourning, suffering, catastrophe, critical interpretation, Walter Benjamin, Theodor Adorno.

\title{
1. Introducción
}

En Contra la interpretación Susan Sontag explica que:

la actual es una de esas épocas en que la actitud interpretativa [the project of interpretation] es en gran parte reaccionaria, asfixiante. La efusión de interpretaciones del arte envenena hoy nuestras sensibilidades. (...) Interpretar es empobrecer, reducir el mundo, para instaurar un mundo sombrío de significados. (Sontag 2005, 30-31)

Con este fragmento la autora pone en palabras el clímax de una sospecha radical, aquella que señala la paradojal dinámica de la razón moderna: en la progresiva racionalización de cada esfera de la experiencia, ella ha devenido impotente, asfixiante, "envenenadora". Frente a la experiencia dolorosa y múltiple que signa las primeras décadas del siglo XX, por un lado, se observa que la racionalidad comienza a recular y, por otro, se advierte la proliferación de discursos declaradores de la impronta esclerótica de esa razón taxativa. Tal agotamiento decanta en la enunciación de programas sensibles, los cuales se pronun-

Revista de Humanidades de Valparaíso, 2021, No 17, 251-269

(c) $(1) \Theta(-)$ CC BY-NC-ND 
Interpretar el sufrimiento: Walter Benjamin, Theodor W. Adorno y la cuestión de la verdad

María Rita Moreno

cian expresamente "en contra" - como muestra el fragmento de Susan Sontag-. En el seno de semejante praxis opositora, la interpretación constituye el blanco contra el cual movilizar el ataque.

La afrenta a la interpretación surge, entonces, fruto de una patente erosión epistemológica impregnada en la atmósfera intelectual del siglo XX. Si el contexto de "una crisis general de la experiencia atraviesa toda la Modernidad" (Vedda 2016, 309), la catástrofe en cuanto marca de la época desborda el ascenso de los fascismos y se extiende a la esfera epistemológica. La crisis de la razón apunta que la escisión sujeto-objeto no cesa de profundizarse; al mismo tiempo, la "decadencia de la cultura occidental" (Spengler 1993, 26) acuña en uno de sus pliegues el deterioro de los lazos racionales con la verdad-objetividad. En efecto, la modernidad tardía expresa su constitución catastrófica en un hecho paradójico: la creciente racionalización de las esferas de la experiencia redunda en la inconsistencia de la razón misma, en la denuncia de que la razón impide la plenitud de la experiencia.

En una línea semejante se despliegan las investigaciones de Walter Benjamin y Theodor Adorno. Aunque sus filosofías no son estrictamente congruentes, ambos pensadores elaboran un abordaje complejo de las "situaciones de modernidad"1 (Jameson 2004, 56) y determinan en ellas una irrecusable crítica de la razón moderna. Los dos filósofos esbozan su Teoría Crítica conforme a la erosión epistemológica de su tiempo histórico, de allí que busquen articular "la divergencia entre concepto y cosa, entre sujeto y objeto, y la irreconciliabilidad entre ambos" (Adorno 2020, 39). Sin embargo, tanto Benjamin como Adorno insisten en la interpretación como vía pertinente mediante la cual desmontar tal dialéctica de la razón moderna.

Cuando Adorno indica que "interpretación [Deutung] de lo que carece de intención mediante composición de los elementos aislados por análisis, e iluminación de lo real mediante esa interpretación: tal es el programa de todo auténtico conocimiento materialista" $(1991,90)$ explicita la afirmación benjaminiana según la cual la tarea del historiador materialista consiste en "la interpretación de los sueños [Traumdeutung]" (2005, 466 [N $4,1]$ ) colectivos. Consecuentemente, resulta por lo menos llamativo que critiquen las aporías de la racionalidad moderna, pero, simultáneamente, reivindiquen la interpretación como praxis filosófica. Más aún si se tiene en cuenta el vector determinante para el pensamiento materialista contenido en la tesis XI de los trabajos de Marx en torno a la filosofía de Feuerbach ${ }^{2}$.

\footnotetext{
${ }^{1}$ Fredric Jameson define "situación de modernidad" como un término narrativo que intenta mantener unidas dentro de sí las características contradictorias de pertenencia e innovación de tal época histórica.

${ }^{2}$ Karl Marx no denuesta la interpretación, sino que tematiza críticamente la disolución de un concepto de filosofía (reflexión recogida por Benjamin y Adorno, tal como esperamos mostrar). Cf. Grüner 2006, 109.
} 
Interpretar el sufrimiento: Walter Benjamin, Theodor W. Adorno y la cuestión de la verdad

María Rita Moreno

¿A qué se debe esta presunta inconsistencia? ¿Por qué tanto en el pensamiento benjaminiano como en el adorniano se critica la razón al tiempo que se restituye la interpretación? En un escenario de debilitamiento epistemológico, Walter Benjamin y Theodor W. Adorno ensayan una crítica de la razón y, desde ella, modulan una epistemología divergente. Nuestra hipótesis afirma que la criticidad de sus desarrollos se fundamenta no tanto en la reformulación de una praxis contra la razón y la interpretación, sino fundamentalmente en la metamorfosis del concepto de verdad. Solo a partir de tal transfiguración pueden comprenderse los tránsitos prácticos con que ambos pensadores configuran la filosofía característica de la Teoría Crítica. Así entonces, este artículo se propone fundamentar que Benjamin y Adorno viabilizan una interpretación crítica en la medida en que identifican la catástrofe moderna que anida en el núcleo temporal de la verdad. A tal fin, proponemos un abordaje dialógico de los aportes de uno y otro pensador con el propósito de tejer con ellos la imagen de su epistemología crítica. En esa dirección, en primer lugar, explicamos la conjugación realizada por ambos filósofos entre núcleo temporal de la verdad y el concepto de verdad negativa; imbricación que procura condensar la constitución subjetivista de la razón. Luego, señalamos la concurrencia del núcleo temporal de la verdad con la producción del sufrimiento. A continuación, determinamos en qué sentido la negatividad de la verdad abre el carácter dialéctico de la catástrofe moderna. Por último, indicamos la necesaria asociación de semejante epistemología crítica a la apocatástasis histórica.

\section{Núcleo temporal de la verdad, duelo y negatividad}

Libro de los Pasajes contiene segmentos en los que se indica expresamente el abordaje benjaminiano de la esfera de lo verdadero. En concreto, su autor explica que:

Hay que apartarse decididamente del concepto de "verdad atemporal". Sin embargo, la verdad no es —como afirma el marxismo — únicamente una función temporal del proceso de conocimiento, sino que está unida a un núcleo temporal, escondido a la vez tanto en lo conocido como en el conocedor. (Benjamin 2005, 465 [N 3, 2])

La indicación de Benjamin llama la atención sobre cierta concepción estática de la verdad (tanto la "atemporal" como la del marxismo) al tiempo que señala la tensión dialéctica que le da forma: el núcleo temporal de la verdad supone simultáneamente una cesura y una remisión recíproca entre la objetividad ("lo conocido") y la subjetividad ("lo conocedor"). La potencia de esta concepción es retomada y desarrollada por Adorno en varios pasajes de sus textos ${ }^{3}$; de hecho, despliega el mismo segmento del Passagenwerk

\footnotetext{
${ }^{3}$ Por ejemplo, en Introducción a la dialéctica (Adorno 2013, 53) o en las "Meditaciones sobre metafísica" de la Dialéctica negativa (Adorno 2005, 340).
}

Revista de Humanidades de Valparaíso, 2021, No 17, 251-269 
Interpretar el sufrimiento: Walter Benjamin, Theodor W. Adorno y la cuestión de la verdad

María Rita Moreno

recién aludido en su Metacrítica de la teoría del conocimiento. En ese contexto Adorno establece que la afirmación del núcleo temporal de la verdad no implica "que haya verdad en la historia, como quiere el relativismo, sino que hay historia en la verdad" $(2012,131)$.

¿Qué es, pues, el núcleo temporal? Con esta expresión Benjamin "se sale de la lógica marxista que hace del conocimiento un momento de poder del sujeto cognoscente, para posibilitar un conocimiento no como poder sino como liberación" (Reyes Mate 1991, 55). Concretamente, Benjamin quiere señalar la tensión irrecusable entre dos tiempos - el tiempo de lo conocido, por un lado, y el tiempo de lo que conoce, por el otro- subyacente a todo acto de conocimiento. En el epicentro de esa tensión el continuo temporal se suspende, se altera la experiencia cognoscitiva y se expone la imagen dialéctica que el historiador materialista persigue. El giro copernicano de la visión histórica implicado en el énfasis del núcleo temporal — dirección definitoria de la filosofía benjaminiana— "significaba por lo demás, y ante todo, que había que darle la vuelta al concepto tradicional de verdad" (Tiedemann 2005, 27).

Así entonces, la indagación atenta al núcleo temporal de lo verdadero delinea un concepto crítico de verdad y, como consecuencia, modifica tanto la crítica de la razón como la praxis racional que pretende acceder a ese núcleo temporal. En tal sentido, Benjamin y Adorno recorren sendas "«metahistoria[s]» de la razón" (Wellmer 2013, 165) con el objeto de determinar el contenido del núcleo temporal de la verdad en el contexto del debilitamiento epistemológico de la modernidad tardía: en La enseñanza de lo semejante Benjamin (2001a, 85) investiga el devenir de las relaciones entre lo conocido y lo conocedor mediante una historización filogenética de la facultad mimética. Adorno, por su lado, — junto a Max Horkheimer — trabaja "en su Dialéctica de la Ilustración un relato que narraría las peripecias racionales" (Echeverría 2010, 46). Ambos filósofos establecen como rasgo característico del decurso de la razón moderna que la tensión entre lo conocido y lo conocedor se disuelve en una preeminencia subjetivista.

En el derrotero benjaminiano, la crítica de la razón moderna identifica en "la naturaleza-sujeto de la conciencia cognitiva, [algo] que aún hay que eliminar" (Benjamin 2001c, 78).

Según explica Benjamin en Sobre el programa de una filosofía venidera (texto concebido en 1918), el subjetivismo - $i$. e., la preeminencia unilateral y determinante de lo que conoce sobre lo conocido - constituye la estructura causante de las aporías de la racionalidad moderna. Por eso, para Benjamin, el programa de una filosofía del porvenir debe asumir la tarea de desmontar "la concepción del conocimiento como relación entre algunos sujetos y objetos, o algún sujeto y objeto" (Benjamin 2001c, 78). Esto porque el subjetivismo racional representa una limitación en la medida en que "no es más que un rudimento metafísico en la teoría del conocimiento; un pedazo de esa «experiencia» chata de esos siglos que se filtró en la teoría del conocimiento" (Benjamin 2001c, 78).

Revista de Humanidades de Valparaíso, 2021, No 17, 251-269

(c) $(1)(9)$ CC BY-NC-ND 
Interpretar el sufrimiento: Walter Benjamin, Theodor W. Adorno y la cuestión de la verdad

María Rita Moreno

¿Por qué la impronta subjetiva del conocimiento es una limitación? Una posible respuesta se encuentra en un texto de la misma época, Sobre el lenguaje en general y el lenguaje de los humanos (Benjamin 2001b). Allí Benjamin indica que el talante subjetivista de la racionalidad resulta problemático porque supone la negación denodada del carácter lingüístico de la objetividad. Dado que "no existe evento o cosa, tanto en la naturaleza viva como inanimada, que no tenga, de alguna forma, participación en el lenguaje" (Benjamin 2001b, 59), la racionalidad moderna, anclada en las determinaciones de la subjetividad, produce el silenciamiento del ser lingüístico de cada cosa. Tal acallamiento representa un acto con "hondas consecuencias sobre la naturaleza y sobre la relación entre ésta y el hombre" (Vedda 2016, 314), pues configura violentamente ${ }^{4}$ la tensión sujeto-objeto. La violencia subjetivista de la razón moderna obtura el lenguaje objetivo al operar una equivalencia entre hablar y juzgar: somete la objetividad al esquema instrumental según el cual cada entidad es subsumida en la abstracción de medio y/o fines (Benjamin 2001b, 62). Así, la razón moderna maximiza su despliegue en la medida en que reduce el circuito de la comunicación a la configuración de su propia subjetividad. En lugar de oír e interpretar el lenguaje objetivo, la razón niega sistemáticamente la objetividad y se pone a sí misma como fundamento y destino.

La racionalidad subjetivista mutila la experiencia del conocimiento $-\mathrm{o}$ sea, produce y reproduce la erosión epistemológica moderna - debido a la "super-determinación [Überbenennung]” (Benjamin 2001b, 73) de la objetividad: super-determinar significa no solo no escuchar el lenguaje objetivo, sino negarlo, condenarlo al duelo causado por el "abandono de las cosas" (Benjamin 2001b, 72). Por consiguiente, mientras que el sujeto juzga racionalmente, "la tristeza de la naturaleza" (Benjamin 2001b, 73) — su duelo y sufrimiento - configura el núcleo de la verdad objetiva. La naturaleza se vuelve muda (Benjamin 2001b, 73) porque no hay quien pronuncie su lenguaje. De esta manera, la super-determinación subjetivista conduce a la crisis racional en tanto que "por medio de palabras señala las cosas" (Benjamin 2001b, 62). La atmósfera epistemológica de la modernidad se define, en consecuencia, por la "violencia subjetivista (...) justificada a partir de una teoría del conocimiento antropomórfica" (Vedda 2012, 10). Ya que "es la intrusión de una subjetividad arbitraria, caracterizada como el mal, lo que vuelve a la naturaleza antes objetiva en triste y muda" (Vedda 2012, 9), la objetividad permanece desconocida en tanto que innombrada.

En la obra de Adorno puede advertirse el modo en que se especifica la configuración de esa super-determinación subjetivista, causa del sufrimiento luctuoso como núcleo de la verdad objetiva. Conforme a la exposición de Dialéctica negativa, "el sufrimiento es objetividad que pesa sobre el sujeto" (Adorno 2005, 28) merced a la "autarquía del concepto" (Adorno 2005, 23) y su forma. Es decir, el núcleo temporal de la verdad objetiva

\footnotetext{
${ }^{4}$ El desarrollo benjaminiano de la Gewalt excede el propósito aquí perseguido. Para un tratamiento específico de este aspecto, cf. https://doi.org/10.24310/Contrastescontrastes.v24i1.6710
} 
Interpretar el sufrimiento: Walter Benjamin, Theodor W. Adorno y la cuestión de la verdad

María Rita Moreno

deviene sufriente porque la super-determinación supone la igualación inmediata de pensar e identificar (Adorno 2005, 17). Dado que la razón procede conforme a la lógica de la identidad decanta, necesariamente, en la exclusión del lenguaje objetivo.

¿Cómo? Adorno indica que el proceso de objetivación se mueve a dos tiempos: por un lado, incluye; por otro, expulsa. La razón objetiva todo aquello susceptible de ser incorporado al esquema conceptual de la identidad, mientras que "todo lo que no se adecue a éste, todo lo cualitativamente distinto, recibe el marchamo de la contradicción [Widerspruchs]" (Adorno 2005, 17). De modo tal que todas las dimensiones de lo real que se adecuen a la forma abstracta y universal del concepto pueden ser elaboradas racionalmente; pero, consecuentemente, las particularidades diferenciales que rehúyen la congruencia con la totalidad implicada en la determinación general del concepto son relegadas a lo irracional. La inclusión de lo identificable y la exclusión de lo contradictorio son, entonces, dos momentos recíprocos de la razón. Pensar supone de suyo no solo conceptualizar lo identificable, sino, en la misma medida, negar lo contradictorio: su proceder "es un «tachar», un «excluir»» (Adorno 2012, 71).

Por lo tanto, el acto de objetivación afianza "el subjetivismo radicalizado" (Adorno 2012, 71) al reforzar "el absolutismo lógico" (Adorno 2012, 71): la primacía del método implica que "lo que no encaja en él aparece al margen como «dato» que espera su puesto y que, si no lo encuentra, es desechado" (Adorno 2012, 47). Así, Adorno muestra que la super-determinación subjetivista señalada por Benjamin opera como "hipostatización de la lógica pura" (Adorno 2012, 71), es decir:

en su ingenuidad respecto a la relación con lo objetivo, la lógica necesariamente se malentiende a sí misma: se atribuye a sí misma, en cuanto forma pura, la rigurosidad que adquiere en el juicio sobre objetos, haciéndose pasar por ontología. (Adorno 2012, 71)

Así entonces, el núcleo temporal de la verdad queda definido por semejante transposición: la objetividad, producida a imagen y semejanza de los esquemas lógicos de la subjetividad super-determinante, se constituye ontológicamente solo como la apariencia de una otredad. El objeto, en cuanto diferencia radical de la subjetividad que pretende conocerlo, es reemplazado por la forma de la subjetividad racional. De esta manera, la razón moderna se muestra como la manifestación del absolutismo subjetivista.

Aún más: Adorno explica que semejante maniobra hipostática sobre el núcleo temporal de la verdad redunda en la configuración de un "concepto residual de la verdad" (Adorno 2012, 71). Conforme a la super-determinación subjetivista, en la modernidad la verdad "aparece como lo que «resta», después de haber sustraído los gastos del proceso 
Interpretar el sufrimiento: Walter Benjamin, Theodor W. Adorno y la cuestión de la verdad

María Rita Moreno

de producción" (Adorno 2012, 71) . La erosión epistemológica de la modernidad, entonces, se vincula a un núcleo temporal de lo verdadero que produce residuos: objetivar es disponer qué se conserva y qué se bota.

El concepto de verdad en cuanto residuo señala la clasificación implicada en el acto ontológico de la super-determinación subjetivista: la razón clasifica la objetividad en dos esferas, la de lo racional-idéntico y la de lo irracional-vestigial. Lo sobrante es desechado en calidad de quantité négligeable (Adorno 2005, 19), esto es, cantidad despreciable accidente, contingencia, error- que demanda un rápido despacho y que, a causa de eso, sufre.

Explicitar los bemoles del concepto residual de la verdad ayuda a comprender no solo la operatividad de la super-determinación subjetivista enunciada por Benjamin, sino, en la misma medida, la alusión al sufrimiento objetivo. La crítica de la razón moderna de Adorno y Benjamin identifica el núcleo temporal de la verdad que en ella opera y determina que su contenido es lo excluido: Benjamin lo nombra como duelo [Trauer]; Adorno lo refiere como negatividad. Por eso, otro de los nombres del concepto crítico de verdad es el de "verdad negativa" (Adorno 2013, 334).

El núcleo temporal de la verdad, entonces, está condicionado por la explicitación de la negatividad y el duelo mientras que, en simultáneo, comprender la negatividad demanda la determinación de la configuración histórica de la verdad. Tal concepto de verdad está a la base de la Teoría Crítica y fundamenta las vías epistemológicas que ella explora. El anudamiento de verdad y duelo-negatividad deja al descubierto la confluencia que Benjamin y Adorno disciernen entre la esfera de lo epistemológico y la esfera de lo histórico-político, ya que la concreción de lo verdadero está sujeta a la concreción de la exclusión racional de lo negativo.

\section{Sufrimiento e interpretación}

A pesar de la diagramación negativa y luctuosa del núcleo temporal de la verdad, la crítica de la razón moderna efectuada por Adorno y Benjamin inquiere la posibilidad de una filosofía venidera ${ }^{6}$ actualizadora de la praxis filosófica ${ }^{7}$. Es decir, aunque el deterioro epistemológico de la modernidad tardía apunta la diagramación residual-negativa de la verdad, la Teoría Crítica benjaminiana y adorniana insiste en la vehiculización de una epistemología, o sea, en la indagación de las vías por las que la razón pueda estrechar lazos con la objetividad sufriente. Claro que, como consecuencia de sus análisis, el desa-

\footnotetext{
${ }^{5}$ Allí mismo Adorno señala que Hegel y Nietzsche se sustraen del concepto residual de la verdad, pero, salvo estas excepciones, afirma que tal concepto es propiedad común de toda la filosofía burguesa.

${ }^{6}$ Tal como Benjamin desarrolla en Para el programa de una filosofía venidera (texto de 1918).

${ }^{7}$ Problema planteado por Adorno en La actualidad de la filosofía (conferencia de 1931).
}

Revista de Humanidades de Valparaíso, 2021, No 17, 251-269

(c) (1) @९ $\mathrm{CC}$ BY-NC-ND 
Interpretar el sufrimiento: Walter Benjamin, Theodor W. Adorno y la cuestión de la verdad

María Rita Moreno

rrollo de una epistemología crítica toma como punto de partida el contenido sufriente del núcleo temporal de la verdad y entiende que su carácter residual altera la praxis racional. En consecuencia, si Benjamin establece que la objetividad se halla entristecida a causa de su silenciamiento sistemático, Adorno advierte que "la necesidad de prestar voz al sufrimiento es condición de toda verdad" $(2005,28)$.

La razón de ello se encuentra en el mismo concepto de verdad negativa: la intelección del anverso residual de la identidad es lo suficientemente fuerte para soportar la construcción de otra epistemología. Dicho de otro modo, ya que la racionalidad subjetivista super-determina el carácter lingüístico de los entes condenándolos al duelo de su silenciamiento, el pensamiento puede mostrar tal discontinuidad subjetiva-objetiva $\mathrm{y}$, desde ella, explorar y exponer el núcleo temporal de lo verdadero en cuanto vestigio sufriente, residuo silenciado, verdad negativa. La convergencia del núcleo temporal de la verdad y sufrimiento señala el entramado histórico-epistemológico de negatividad y duelo: desde allí, la Teoría Crítica de Benjamin y Adorno aspira a "rodear" la verdad (Benjamin 2012, 62) sin desconocer la hipóstasis de la surge.

En ese contexto, la epistemología crítica afirma que "de lo que de la verdad se toca mediante conceptos más allá de su abstracto cerco no puede tener ningún otro escenario que lo por él oprimido, despreciado y rechazado" (Adorno 2005, 21). Y es esta, precisamente, la causa por la que Benjamin y Adorno apuntan la efectividad de una epistemología en la forma de cierta interpretación de lo sufriente y enlutado. Retomamos el interrogante planteado al inicio: ¿por qué la crítica de la razón moderna acuñada en el pensamiento benjaminiano y adorniano restituye la interpretación? ¿Cuál es el vínculo triangulado entre el núcleo luctuoso-negativo de la verdad, la esclerosis epistémica del siglo XX y la interpretación efectuada en el marco de la Teoría Crítica?

Para una epistemología capaz de escuchar lo sufriente y dar voz a lo acallado por la super-determinación, la inconmensurabilidad sujeto-objeto representa no solo el límite de la razón moderna, sino aún más y al mismo tiempo, el resquicio desde donde combatir la disposición subjetivista de la razón. Si el núcleo temporal marca una tensión entre lo conocido y lo que conoce, la desavenencia entre la subjetividad y la objetividad se determina como dialéctica. De allí que el límite (la limitación implicada en la inconmensurabilidad moderna sujeto-objeto) sea una instancia no meramente restrictiva, sino más bien transformativa: como explica Benjamin, el límite vuelto contra sí mismo materializa un rito de paso, una experiencia del umbral (2005, 495 [O 2 a, 1]; y "el umbral es una zona (...) el término 'umbralar' [schwellen] implica cambio, transición”' (2005, 495 [O 2 a, 1]).

La transformación contenida en la interpretación del sufrimiento no abandona la contradicción sujeto-objeto; por el contrario, merced al concepto de verdad negativa, ensaya una epistemología atravesada por el duelo de la objetividad. Entonces, si se persigue la "libertad para el objeto" (Adorno 2005, 37) cercenada por el concepto (Benjamin 2012, 75), la aproximación crítico-racional a lo verdadero supone el desafío de experimentar lo

Revista de Humanidades de Valparaíso, 2021, No 17, 251-269

(c) $(1)(9)$ CC BY-NC-ND 
Interpretar el sufrimiento: Walter Benjamin, Theodor W. Adorno y la cuestión de la verdad

María Rita Moreno

no-simultáneo, lo no-idéntico, lo no-dicho. Dirigir la atención al residuo — al fragmento expulsado por la hipóstasis lógica ejecutada por la racionalidad subjetivista- es, precisamente, la tarea de la interpretación en cuanto praxis de la epistemología crítica benjaminiana y adorniana.

En efecto, la Teoría Crítica asume el reto epistemológico de captar aquello que no sigue el ritmo del "continuum pseudológico" (Benjamin 2012, 77) y, de esa manera, busca mostrar el sufrimiento como el núcleo moderno de la verdad. Frente a la tiranía de una racionalidad subjetivista, la interpretación de lo sufriente y desoído asoma como la instancia crítico-dialéctica: crítica, porque el pensar sigue empeñado en relacionarse con la verdad; dialéctica, porque esa verdad es buscada en los fragmentos vestigiales, en los residuos negativos, en las contradicciones. De hecho:

si, en efecto, la representación de la dialéctica tiene un núcleo temporal, (...) entonces esto significa que es esencialmente también una dialéctica de momentos no simultáneos, esto es, que a partir del desarrollo temporal debe entender precisamente también aquello que, si ustedes quieren, no ha mantenido el ritmo del avance histórico. (Adorno 2013, 259)

Esto no significa que la interpretación crítica procure volver a un germen sagrado, profanado más tarde por la razón moderna. Al contrario, la posición epistemológica que se orienta por el núcleo temporal de lo verdadero empuña esa misma racionalidad subjetivista y la vuelve contra sí misma: se propone mostrar que la homogeneidad presupuesta en la lógica identitaria de la razón está, en realidad, repleta de cicatrices. La Teoría Crítica actualiza la posibilidad de una epistemología no solo cuando se apropia del núcleo histórico de lo verdadero, sino, aún más, cuando ese núcleo temporal es mostrado en su condición de verdad negativa. Este es el sentido propio y expreso de la construcción de una teoría del conocimiento enunciada por ambos pensadores: la razón modula su posibilidad de vincularse con la objetividad en la medida en que asume como su materia la historia de las contradicciones desde el punto de vista de aquello que constituye lo verdadero, es decir, desde el punto de vista de lo que sufre.

Si la interpretación crítica persiste en su referencia a la verdad, lo hace solo en la medida que la verdad no puede concebirse ya como algo cosificado. El concepto de verdad negativa ubica la interpretación en el terreno lo acallado. Esto es, aquello destilado racionalmente como vestigio es explicitado en las causas y determinaciones de su constitución sufriente. La interpretación busca mostrar el núcleo temporal de la verdad es la no-verdad; que "falsum index sui et veri" (Adorno 2013, 335) significa que cada fenómeno puede ser interpretado en su incapacidad de subsunción absoluta e inmediata a un concepto positivo que pretende identidad consigo mismo. Se trata de trastocar la praxis racional a partir de la negatividad implicada en la verdad. Pero, ¿qué significa esto? 
Interpretar el sufrimiento: Walter Benjamin, Theodor W. Adorno y la cuestión de la verdad

María Rita Moreno

\section{Dialéctica de la catástrofe y dislocación del continuum racional}

La determinación negativa del núcleo temporal de la verdad abre un horizonte, pues alterar el concepto de verdad supone alterar las expresiones, derivas y despliegues de la racionalidad. Los vericuetos de esta alteración pueden ser indagados leyendo en clave epistemológica la tesis IX de Sobre el concepto de historia (Benjamin 2006) ${ }^{8}$. Ya que la identificación de verdad y sufrimiento ofrece el espectáculo trágico de la catástrofe, la mirada estupefacta del Angelus Novus (Benjamin 2006, 155) puede ser traspuesta como la mirada filosófica ante el concepto de verdad negativa.

Lo catastrófico, índice del escenario histórico del siglo XX, se materializa también en la infausta producción racional de residuos lógico-ontológicos, condición nuclear de la verdad. La epistemología crítica, por lo tanto, procura mirar como mira el ángel: como un alegorista. El complejo concepto de "alegoría" — determinado por Benjamin en distintos lugares de su obra - se define en relación a los fragmentos expulsados tanto por la lógica del continuo progresivo histórico ${ }^{9}$ como por la del continuo subjetivista racional. Según Benjamin, la alegoría expresa una dialéctica: por un lado, presenta "una tendencia regresiva" (Benjamin 2005, 339 [ $\mathrm{J}$ 57, 3]) en tanto que no se interesa por suprimir lo que se desmorona; por otro lado y al mismo tiempo, presenta "una tendencia progresiva" (Benjamin 2005, 339 [J 57, 3]) según la cual expulsa la apariencia de totalidad de un orden dado.

De esta manera, "lo que es afectado por la intención alegórica queda separado de los contextos de la vida: resulta a la vez destruido y conservado. La alegoría se aferra a las ruinas" (Benjamin 2005, 337 [J 56, 1]) y tal es la dirección de la interpretación formulada en los términos de Benjamin y Adorno. Aunque "bien quisiera él detenerse, despertar a los muertos y recomponer los fragmentos" (Benjamin 2006, 155), el pensamiento mira los residuos y busca comprenderlos en su calidad de fragmentos expulsados del territorio de la identidad.

En la medida en que advierte la super-determinación subjetivista de la que surge la quantité négligeable, la epistemología crítica desdobla el propio núcleo de la verdad al advertir la dimensión dialéctica de la catástrofe racional. La interpretación regida por el concepto de verdad luctuosa-negativa hace del límite un umbral porque no se detiene al mostrar las consecuencias de la racionalidad moderna: busca torcer la fuerza de la expulsión contra sí misma. En la tensión irresoluble de potencias centrífugas y centrípetas, la epistemología crítica lee un huracán, aquel ante el que se espanta el Angelus y arremolina sus alas. En esa dialéctica condensativa de fuerzas, la interpretación crítica se arroja al poder [Gewalt] de la verdad (Benjamin 2012, 70) y destapa la dialéctica de la catástrofe

\footnotetext{
${ }^{8}$ Después de todo, el texto fue concebido como el "armazón teórico" introductorio del Libro de los Pasajes articulado en torno a un eje epistémico y otro de orden político. Cf. Reyes Mate 2006, 13-19.

${ }^{9}$ La indagación benjaminiana de la filosofía de la historia se concibe en estrecha relación con una teoría del conocimiento. En función de nuestro objetivo, aquí nos concentramos en el último elemento.
} 
Interpretar el sufrimiento: Walter Benjamin, Theodor W. Adorno y la cuestión de la verdad

María Rita Moreno

racional. De esa manera, expone que "catástrofe" alude a un suceso que produce mucho daño, pero, no obstante, al mismo tiempo, también refiere un acontecimiento inesperado: la catástrofe indica un hecho desgarrador en el continuo racional, es decir, señala que el sufrimiento es capaz de romper la continuidad lógica.

Así entonces, lo expulsado por la razón subjetivista, lo silenciado por la super-determinación racional, se hace escuchar desde su propia condición de fragmento excluido. Con ello, la epistemología que persigue un restablecimiento de las relaciones entre razón y realidad se alimenta "de la posibilidad, de ningún modo garantizada, de la ruptura de la continuidad a través de una catástrofe dislocadora" (Forster 2014, 378). La línea epistemológica ensayada por Walter Benjamin y Theodor Adorno hace de la catástrofe del sufrimiento, de la verdad en cuanto negatividad y duelo, el programa de una epistemología crítica. Ambos filósofos denuncian la naturaleza catastrófica del despliegue racional de la modernidad, pero sin perder de vista la potencia — emanada de la misma situación catastrófica- mediante la que cada vestigio es capaz de descoyuntar su propia expulsión.

¿A qué alude esto? Si "la redención se aferra a la pequeña grieta en la catástrofe continua" (Benjamin 1992, 205), la interpretación de lo ocluido conduce a la constatación del hecho negativo por antonomasia: el núcleo temporal de lo verdadero no solo manifiesta la movilidad histórica de cada cosa, sino, fundamentalmente, cristaliza el "primado de la historia sobre el ser" (Adorno 2013, 46). El giro copernicano de la epistemología crítica anida, precisamente, en efectuar el vuelco dialéctico mediante el que "la política obtiene el primado sobre la historia"10 (Benjamin 2005, 294 [K 1, 2]); es decir, en la interpretación dirigida a darle voz al sufrimiento elaborado en la producción de la verdad. Ante la lógica que se hace pasar por ontología, la epistemología crítica interpreta lo expulsado y da así voz al mutismo objetivo. Empero, esa voz silenciada no es expuesta en cuanto "el verdadero ser" objetivo, pues no se trata de reponer una verdad primigenia, mancillada posteriormente por la razón moderna. Al contrario, si la interpretación de la verdad negativa vuelve evidente la cosificación de la objetivación, el ejercicio de una epistemología crítica consiste en luchar contra la cosificación comprendiéndola en su propia necesidad. Por lo tanto, interpretar críticamente es "lo mismo que entender la necesidad histórica de una cosa en todos sus niveles” (Adorno 2013, 49).

El momento transformador implicado en el umbral moderno de la razón no acontece en la suspensión "de" la negatividad de la verdad, sino en la suspensión "en" esa negatividad. La óptica distintiva de la interpretación diagramada por Benjamin y Adorno consiste en sostener su epistemología sobre el hecho histórico determinante de la modernidad: "que no hay objeto que, precisamente en la medida que se nos presenta como objeto de-

\footnotetext{
${ }^{10}$ Aunque Adorno enuncia el primado de la historia sobre el ser y Benjamin el de la política sobre la historia, ambas expresiones apuntan horizontes próximos: Adorno enfatiza que el núcleo temporal de la verdad expresa la movilidad histórica de cada cosa; Benjamin, que la preeminencia política quiere deshacer la inmovilidad de los hechos.
}

Revista de Humanidades de Valparaíso, 2021, No 17, 251-269

(c) $(1)(9)$ CC BY-NC-ND 
Interpretar el sufrimiento: Walter Benjamin, Theodor W. Adorno y la cuestión de la verdad

María Rita Moreno

terminado, no contenga en sí mismo también pensar, en sí mismo sujeto" (Adorno 2013, 339) así como no hay totalidad alguna que pueda ser siquiera concebida si no es en su mediación con los fragmentos que expulsa fuera de sí.

Esta perspectiva epistemológica asume el núcleo temporal de la verdad porque no temporiza la verdad meramente, sino que se sumerge en la materia de la historia constitutiva de las esferas subjetiva y objetiva y descubre allí la verdad como catástrofe. Aun así, la interpretación que ambos construyen no intenta limpiar esa verdad de sus jirones catastróficos; al contrario, el empeño se direcciona para embarrar lo catastrófico con su verdad y viceversa. Se trata de aprehender las heridas objetivas en la ejecución de un doble movimiento: primeramente, conocer los fenómenos singulares dentro de la totalidad de la que extraen su sentido (por estar incluidos o expulsados de esta totalidad) al tiempo que, en segundo lugar, esa totalidad, es exhibida como fragmentaria a partir de los residuos que produce. Así entonces, la epistemología crítica de Benjamin y Adorno asesta el carácter problemático de la razón moderna instalándose en la savia misma de esa problematicidad:

El curso de la historia como se presenta bajo el concepto de catástrofe no puede, en realidad, demandar mayor atención a quien reflexiona que el caleidoscopio en la mano de un niño, en el que lo ordenado se derrumba para formar un nuevo orden con cada giro.

Esta imagen está totalmente justificada. Los conceptos de los gobernantes fueron siempre los espejos gracias a los cuales se formó la imagen de un «orden». —El caleidoscopio debe ser destruido. (Benjamin 1992, 177)

\section{Verdad negativa y apocatástasis histórica}

Contra la super-determinación racional conforme a la lógica de la identidad, la interpretación crítica afirma que "un conocimiento que quiere el contenido quiere la utopía" (Adorno 2005, 62-63). Sin embargo, "lo nuevo es el anhelo de lo nuevo, pero apenas lo nuevo mismo: de esto adolece todo lo nuevo" (Adorno 2004, 50): lo que se presenta como utopía es, necesariamente, algo negativo frente al dictamen de lo idéntico. Es decir, justo porque se opone a lo existente está también sometido a lo existente: la utopía no puede concebirse si no es en relación con aquello a lo que se opone.

"Querer la utopía" significa, entonces, establecer el pensamiento en el núcleo temporal de la verdad con el objetivo de extraer su luto y negatividad; implica asentarse en medio de la catástrofe moderna para torcer su rasgo inesperado, para cepillarla a ella también a contrapelo. El sufrimiento en cuanto materia del núcleo de la verdad manifiesta que "la posibilidad real de la utopía (...) se une en una cumbre extrema con la posibilidad de la catástrofe total" (Adorno 2004, 51). Por lo tanto, la epistemología de Adorno y Benjamin, en la medida en que procura viabilizar un acceso racional a la verdad, demanda un espe-

Revista de Humanidades de Valparaíso, 2021, No 17, 251-269

(c) $(1)(9)$ CC BY-NC-ND 
Interpretar el sufrimiento: Walter Benjamin, Theodor W. Adorno y la cuestión de la verdad

María Rita Moreno

cífico trabajo con el pliego luctuoso devenido objetividad: apoderarse de esa negatividad como lo "repleto de ahora" (Benjamin 2006, 223) constituye el desafío epistemológico de una racionalidad crítica en el contexto de la modernidad.

Consecuentemente, en el seno de la Teoría Crítica promovida por Theodor Adorno y Walter Benjamin puede vislumbrarse la latencia de una utopía epistemológica: el ensueño epistemológico de la interpretación estriba en abrir con la razón y sus posibilidades aquello expulsado por la razón misma. En ese sentido, "lo urgente para el concepto es aquello a lo que no llega, lo que su mecanismo de abstracción excluye" (Adorno 2005, 19).

En las estrías reveladoras de las tensiones y conflictos que marcan la praxis racional la Teoría Crítica establece una zona de trabajo caracterizada por la puesta en marcha de una interpretación crítica. Frente al proceso moderno de diferenciación racional, ella se empecina en mostrar que la expulsión y el acallamiento implicados en la verdad luctuoso-negativa quiebran la totalidad de la continuidad (lógica u ontológica). Su hilo conductor, entonces, es dado por el sufrimiento de los condenados al silencio de su carácter lingüístico. Obstinarse en el sufrimiento constituye el modo crítico de abrir dialécticamente una instancia distinta a la catástrofe del sufrimiento. Entonces, ¿cómo conducir la catástrofe a lo otro de sí mismo? La razón encauza su posibilidad interpretativa en la tarea de acercar lo ocluido, lo silenciado, lo desechado y, desde este anverso negativo de lo verdadero, hace posible la "apocatástasis de la historia" (Benjamin 2005, 462 [N 1 a, 3]), determinante de la epistemología crítica.

La apocatástasis de la historia constituye, entonces, el anzuelo de la interpretación tal como la formulan Adorno y Benjamin: ella es, concretamente, el gozne mediante el cual la dirección de la tiranía subjetivista es torcida y desviada. Definida como el movimiento de volver a reunir "lo demasiado pronto y lo demasiado tarde, el primer comienzo y la última ruina" (Benjamin 2005, 708 [a 1, 1]), la apocatástasis de la historia constituye la cristalización del anudamiento entre epistemología crítica y modernidad.

¿De qué se trata? Según explica Benjamin, cada época es susceptible de ser distinguida en las dicotomías que la constituyen. Luego, en cada una de esas dicotomías es posible discernir una parte fructífera y una parte infecunda, una parte positiva de una parte ocluida y negativa:

Incluso únicamente podrá perfilarse con claridad el contorno de esta parte positiva si se la contrasta con la negativa. Pero toda negación, por otra parte, vale solo como fondo para perfilar lo vivo, lo positivo. De ahí que tenga decisiva importancia volver a efectuar una división en esta parte negativa y excluida de antemano, de tal modo que con desplazar el ángulo de visión (¡pero no la escala de medida!) salga de nuevo a la luz del día, también aquí, algo positivo y distinto a lo anteriormente señalado. Y así in infinitum, hasta que, en una apocatástasis de la historia, todo el pasado haya sido llevado al presente. (Benjamin 2005, 461-462 [N 1 a, 3]) 
Interpretar el sufrimiento: Walter Benjamin, Theodor W. Adorno y la cuestión de la verdad

María Rita Moreno

La epistemología adorniana y benjaminiana insiste en la interpretación crítica porque ella es la vía adecuada para ejecutar la apocatástasis sobre los fragmentos expulsados de la verdad: ella modifica la acción racional (es decir, evita reproducir la tiranía subjetivista de la super-determinación) en la medida en que enfatiza la fuerza negativa sobre lo negado para así negar lo afirmado.

Por supuesto que la negatividad no se asume como un peldaño en la larga caminata de una historia universal. La diferencia entre el sujeto y el objeto - diferencia zanjada paradójicamente, dialécticamente, por una rigurosa lógica identitaria - hace de la contradicción entre ambos extremos el "index falsi de la realidad" (Bonnet 2007, 38); es decir, el índice de la deficiencia de la razón moderna. Esta contradicción habilita, entonces, la dialéctica suspendida entre lo cerrado y lo abierto, lo dicho y lo callado, lo idéntico y lo negativo, lo reproductor y lo utópico.

En consecuencia, la faceta transformadora de la negatividad consiste en la suspensión de la mirada alegórica, i. e., la interpretación crítica de lo ocluido sufriente. La relación de una racionalidad con el núcleo temporal de la verdad, entonces, no opera en el pensamiento de Adorno y Benjamin en el sentido de una adaequatio rei et intellectus: la construcción de una epistemología crítica no aborda la verdad negativa como acomodándose a sus atributos esenciales. La epistemología actualizada en la forma de una interpretación crítica puede darle voz al sufrimiento en la medida en que advierte no solo los límites de su medio (los límites de la razón moderna), sino, cabalmente, en la medida en que asienta su trabajo en la sustancia histórica configuradora de la modernidad: la negatividad. Frente a ella, no procura super-determinarla. Es decir, no la interpreta con el objetivo de definirla y subsumirla una vez más bajo los universales abstractos producidos por la racionalidad y su lenguaje obliterante. Al contrario, el desafío de efectuar una apocatástasis capaz de apropiarse de la negatividad supone suspender la tendencia determinadora de la racionalidad, accionar su freno de emergencia (Benjamin 2006, 307) y así interrumpir el continuum epistemológico que da forma a la modernidad.

\section{Conclusiones}

Al inicio de nuestro escrito, afirmamos que la epistemología diagramada a dos tiempos por Walter Benjamin y Theodor Adorno extrae su originalidad y su carácter incisivo del particular abordaje del concepto de verdad que ambos realizan. De su crítica de la razón moderna no deducen una oposición a la razón ni una praxis teórica ajena a la esfera racional; más bien, hacen implosionar el concepto de verdad y desde allí extraen la potencia para abrir la posibilidad de una relación racional con la objetividad. Tal vínculo se concreta, como hemos procurado mostrar, atendiendo al núcleo temporal de la verdad; esto es, como interpretación crítica de los residuos emanados del concepto de verdad negativa. 
Interpretar el sufrimiento: Walter Benjamin, Theodor W. Adorno y la cuestión de la verdad

María Rita Moreno

Para fundamentar esta afirmación, en primer lugar, expusimos la modulación del núcleo temporal de la verdad como negatividad y duelo. ¿De qué manera se conjuga la vertiente sufriente como vector definitorio de la modernidad con la dimensión epistemológica de la experiencia? Elucidamos que ambos filósofos explicitan que el sufrimiento deviene el núcleo temporal de lo verdadero debido a la super-determinación subjetivista y la hipóstasis lógica en la que ella se sostiene. Benjamin establece que la racionalidad subjetivista supone la super-determinación de la experiencia desde el punto de vista de la subjetividad; por lo tanto, el duelo adviene como consecuencia del enmudecimiento del carácter lingüístico de los diversos entes. Adorno especifica esa super-determinación acalladora al indicar que se ejecuta según la lógica de la identidad. La función de la identidad la razón moderna expulsa vestigios al terreno de lo irracional e ilógico. La verdad, de carácter residual, es modulada en cuanto verdad negativa. Por eso, la epistemología adorniana y benjaminiana tiene como objetivo dar voz a lo acallado mediante su interpretación.

Luego, nuestro trabajo intentó explicar por qué la verdad residual, productora de fragmentos luctuosos, se vincula con el carácter dialéctico de la catástrofe moderna. Dado que juzgar la decadencia cultural de inicios del siglo XX como algo cerrado supone repetir el juicio del progreso en su réplica invertida, Benjamin y Adorno ensayan un abordaje divergente del estado catastrófico capaz de desdoblar su potencia dislocadora. Esto se sigue de nuestra propuesta de transponer la mirada alegórica del Angelus Novus en el ámbito epistemológico. Afirmamos que el concepto de verdad luctuoso-negativa promueve una identificación entre tal ámbito y el sufrimiento ofrecido por el espectáculo trágico de la catástrofe, jurisdicción de la figura angélica. Interpretar sería, entonces, virar la mirada sobre los fragmentos emanados del continuo epistemológico — asegurado él por la lógica de la identidad-.

Ambos filósofos comprenden la catástrofe como la realidad constitutiva de la verdad, por eso procuran reunir los fragmentos expulsados por las propias maniobras de la razón y reordenarlos al estilo de un mosaico: juntando sus añicos para construir una imagen distinta. El tránsito anunciado recae en la suspensión epistemológica en el momento de la negatividad. El pensamiento asentado en la negatividad busca no totalizar el fragmento ni hipostasiar la totalidad, al tiempo que no absolutiza las determinaciones puestas por el sujeto ni eterniza las condiciones bajo las que aparecen los objetos.

Indicamos seguidamente que la interpretación crítica diagrama su especificidad en su asunción del primado de la historia y la política sobre el ser, pues persigue una y otra vez exponer el núcleo temporal de lo verdadero. La epistemología benjaminiana y adorniana se zambulle en el devenir histórico de la razón y, a partir de allí, descubre la verdad como catástrofe. Empero, no busca sobreseer a la verdad de su núcleo de negatividad. Lejos de borrar la historia, la posición epistemológica que se orienta por el núcleo temporal de lo

Revista de Humanidades de Valparaíso, 2021, No 17, 251-269

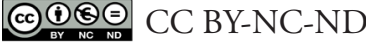


Interpretar el sufrimiento: Walter Benjamin, Theodor W. Adorno y la cuestión de la verdad

María Rita Moreno

verdadero empuña las aporías de la racionalidad moderna y las vuelve contra sí mismas: se propone exponer que la homogeneidad presupuesta en la lógica identitaria de la razón está, en realidad, repleta de cicatrices.

Hacer de esas cicatrices las huellas de la razón conduce a la efectuación de la apocatástasis: si se mide en su peso el carácter antagónico sujeto-objeto y se advierte que los vestigios proscritos claman expresión de su sufrimiento, el pensamiento se ve impelido a mostrar la discontinuidad que constituye el anverso oculto del continuo epistemológico garantizado por la super-determinación subjetivista. La Teoría Crítica actualiza la interpretación, entonces, no solo cuando se apropia del referido núcleo histórico de lo verdadero, sino, aún más, cuando ese núcleo temporal es mostrado en su condición de verdad negativa. Así entonces, las filosofías de Benjamin y Adorno persisten en su referencia a la verdad en la medida en que ya no la conciben como algo cosificado, estático, sino como algo vivo y en movimiento: su vitalidad la extrae del lenguaje de los fragmentos desechados.

Dado que lo verdadero ha llegado a confluir con el sufrimiento, el pensamiento de Adorno y Benjamin se detiene no solo en las estructuras históricas determinantes del núcleo temporal de la verdad, sino que, además, el pensamiento de ambos, históricamente modulado, conduce con su propio ritmo a la negatividad incrustada en el devenir y maniobra desde allí la apocatástasis histórica. El concepto de verdad de la Teoría Crítica es un concepto de verdad negativo porque se determina, precisamente, mediante la acción directa de aquello acallado. Esto es, aquello destilado como vestigio fragmentario de la historia es explicitado en las causas y determinaciones de su constitución sufriente. Este es el sentido más riguroso de interpretar lo verdadero en su estricta unión con el sufrimiento: cada uno de los fenómenos es cuestionado en sí mismo y demostrado en su propia no verdad; esto es, en su incapacidad de subsunción absoluta e inmediata a un concepto positivo que pretende identidad consigo mismo. En un mundo de escisiones contradictorias, denunciar la identidad constituye el momento decisivo de la epistemología crítica.

La interpretación emanada de esta perspectiva epistemológica se abre camino tamizando lo verdadero (objeto de la crítica) con el peso de lo anacrónico (contenido en el desandar los fuelles contradictorios de la historia). Obstinarse en el sufrimiento constituye el modo crítico de abrir dialécticamente una instancia distinta a la del sufrimiento. La Teoría Crítica, expresión de una racionalidad que se ha encontrado con la negatividad, entiende que su "método es el rodeo" (Benjamin, 2012, 62) y hace de la interpretación su medio racional. De ese modo, la razón configura en los fragmentos luctuosos el territorio de su trabajo: lo propio de la interpretación crítica en cuanto actualidad de la filosofía consiste en la exposición de la lógica productora de esos fragmentos.

Revista de Humanidades de Valparaíso, 2021, No 17, 251-269

(c) $(1)(9)$ CC BY-NC-ND 
Interpretar el sufrimiento: Walter Benjamin, Theodor W. Adorno y la cuestión de la verdad

María Rita Moreno

\section{Referencias bibliográficas}

Adorno, Theodor (1991). Actualidad de la Filosofía. En Th. Adorno, Actualidad de la filosofía, pp. 73-102. Barcelona: Paidós.

Adorno, Theodor (2004). Teoría estética. Madrid: Akal.

Adorno, Theodor (2005). Dialéctica negativa. La jerga de la autenticidad. Madrid: Akal.

Adorno, Theodor (2012). Sobre la metacrítica de la teoría del conocimiento. Tres estudios sobre Hegel. Madrid: Akal.

Adorno, Theodor (2013). Introducción a la dialéctica. Buenos Aires: Eterna Cadencia.

Adorno, Theodor (2020). Lecciones sobre dialéctica negativa: fragmentos de las lecciones de 1965-1966. Ciudad Autónoma de Buenos Aires: Eterna Cadencia.

Benjamin, Walter (1992). Zentralpark. En W. Benjamin, Cuadros de un pensamiento, pp. 173-218. Buenos Aires: Imago Mundi.

Benjamin, Walter (2001a). La enseñanza de lo semejante. En W. Benjamin, Iluminaciones $I V$, pp. 85-89. Madrid: Taurus.

Benjamin, Walter (2001b). Sobre el lenguaje en general y sobre el lenguaje de los humanos. En W. Benjamin, Iluminaciones IV, pp. 59-74. Madrid: Taurus.

Benjamin, Walter (2001c). Sobre el programa de la filosofía venidera. En W. Benjamin, Iluminaciones $I V$, pp. 75-84. Madrid: Taurus.

Benjamin, Walter (2005). Libro de los Pasajes. Madrid: Akal.

Benjamin, Walter (2006). Sobre el concepto de historia. En M. Reyes Mate, Medianoche en la historia, pp. 49-302. Madrid: Trotta.

Benjamin, Walter (2012). Origen del Trauerspiel alemán. Buenos Aires: Gorla.

Bonnet, Alberto (2007). Antagonismo y diferencia: la dialéctica negativa y el posestructralismo ante la crítica del capitalismo contemporáneo. En J. Holloway, F. Matamoros, S. Tischler (comps.), Negatividad y revolución. Theodor W. Adorno y la política, pp. 37-72. Buenos Aires: Herramienta y México: Universidad Autónoma de Puebla.

Echeverría, Bolívar (2010). Modernidad y blanquitud. México D. F.: Ediciones Era.

Forster, Ricardo (2014). La travesía del abismo. Mal y Modernidad en Walter Benjamin. Ciudad Autónoma de Buenos Aires: Fondo de Cultura Económica.

Jameson, Fredric (2004). Una modernidad singular. Ensayo sobre la ontología del presente. Barcelona: Gedisa.

Reyes Mate, Manuel (1991). Benjamin o el primado de la política sobre la historia. Isegoría, 4, 49-73. https://doi.org/10.3989/isegoria.1991.i4.353

Revista de Humanidades de Valparaíso, 2021, No 17, 251-269

(c) $(1)(9)$ CC BY-NC-ND 
Interpretar el sufrimiento: Walter Benjamin, Theodor W. Adorno y la cuestión de la verdad

María Rita Moreno

Sontag, Susan (2005). Contra la interpretación. Buenos Aires: Alfaguara.

Spengler, Oswald (1993). La decadencia de Occidente. Barcelona: Planeta.

Tiedemann, Rolf (2005). Introducción del editor. En W. Benjamin, Libro de los Pasajes, pp. 7-33. Madrid: Akal.

Vedda, Miguel (2012). Introducción: Melancolía, transitoriedad, utopía. Sobre El origen del Trauerspiel alemán. En W. Benjamin, Origen del Trauerspiel alemán, pp. 5-51. Buenos Aires: Gorla.

Vedda, Miguel (2016). Crisis del lenguaje y ocaso de la experiencia en Walter Benjamin y Siegfried Kracauer. Constelaciones. Revista De Teoría Crítica, 6(6), 308-321. $\mathrm{http}: / /$ constelaciones-rtc.net/article/view/871

Wellmer, Albrecht (2013). Líneas de fuga de la modernidad. Buenos Aires: Fondo de Cultura Económica, Universidad Autónoma Metropolitana. 
